\title{
METODE ISOLASI YANG MUDAH DALAM ISOLASI SENYAWA 乃-KAROTEN DARI LABU KUNING (Cucurbita moschata Duch ex Poiret)
}

\author{
Rollando Rollando *, Muhammad Hilmi Afthoni \\ Program Studi Farmasi, Fakultas Sains dan Teknologi, Universitas Ma Chung \\ Jl. Villa Puncak Tidar Blok N-01, Malang-Jawa Timur Indonesia-65151 Telp: (0341) 550171 \\ "Email: ro.llando@machung.ac.id
}

\section{INTISARI}

Labu kuning (Cucurbita moschata Duch ex Poiret), buah yang mengandung beberapa senyawa, memiliki aktivitas untuk melindungi tubuh manusia dari radikal bebas. Beta karoten (provitamin A) diakui sebagai senyawa antioksidan. Antioksidan bisa melindungi tubuh dari kerusakan kardiovaskular yang disebabkan oleh radikal bebas. Tujuan dari penelitian ini adalah untuk mengisolasi senyawa beta karoten dan menguji kemurnian isolat beta karoten yang diperoleh menggunakan DR-UV dan spektrofotometri inframerah. Labu kuning diekstraksi menggunakan aseton : petroleumeter dengan rasio (1: 1). Identifikasi beta karoten dari ekstrak dilakukan menggunakan KLT dengan fase gerak etanol: aseton: n-hexane dengan rasio (2:1:1) dan scan spectrum menggunakan spektofotometer UV-Vis. Beta karoten di identifikasi hasil elusi KLT pada UV 254 dan $366 \mathrm{~nm}$ yang menunjukkan adanya 2 spot. Deteksi spektra beta karoten dilakukan pada rentang 350 hingga $550 \mathrm{~nm}$ dan diperoleh puncak beta karoten pada panjang gelombang 234 $\mathrm{nm}$. Proses pemurnian ekstrak dilakukan menggunakan KLT Preparatif dengan fase gerak etanol: aseton: $\mathrm{n}$-hexane dengan rasio $(2: 1: 1)$ dan diperoleh isolat yang dibersihkan terlebih dahulu menggunakan kloroform: metanol perbandingan 1:1. Isolat dikeringkan dan diuji menggunakan DR-UV dan spektrofotometri inframerah. Isolat dari ekstrak labu mengandung beta karoten yaitu zeaxanthin.

Kata kunci: labu kuning; beta karoten; isolasi

\section{ABSTRACT}

Pumpkin (Cucurbita moschata Duch ex Poiret), a fruit that contains several compounds, has activities to protect the human body from free radicals. Provitamin $A$ is recognized as an antioxidant compound. Antioxidants can protect the body's damage caused by free radicals. The purpose of this study was to isolate beta carotene compounds and test the purity of beta carotene isolates obtained using DR-UV and infrared spectrophotometry. Pumpkin is extracted using acetone: petroleum ether with a ratio (1: 1). Identification of beta carotene from extracts was carried out using TLC with the mobile phase of ethanol: acetone: $n$-hexane with a ratio (2: 1: 1) and scan spectrum using a UV-Vis spectrophotometer. Beta carotene was identified as the result of TLC elution on UV 254 and $366 \mathrm{~nm}$ which showed 2 spots. Detection of beta carotene spectra was carried out in the range of 350 to $550 \mathrm{~nm}$ and obtained beta carotene peaks at wavelength $x \mathrm{~nm}$. The extract purification process was carried out using Preparative TLC with the mobile phase of ethanol: acetone: n-hexane with a ratio (2: 1: 1) and obtained isolates cleaned first using chloroform: methanol ratio of 1: 1. The isolates were dried and tested using DR-UV and infrared spectrophotometry. Isolates from Cucurbita moschataDuch ex Poiret extract) contain beta carotene, zeaxanthin.

Keywords: pumpkin; beta carotene; isolation 
*Corresponding author:

Rollando

Program Studi Farmasi, Fakultas Sains dan Teknologi, Universitas Ma Chung

Jl. Villa Puncak Tidar Blok N-01, Malang-Jawa Timur Indonesia-65151

Email: ro.llando@machung.ac.id

\section{PENDAHULUAN}

Karotenoid dikenal sebagai senyawa yang luas distribusinya, keragaman struktural dan berbagai fungsi. Lebih 600 karotenoid tidak termasuk isomer cis- dan trans-, terlah diisolasi dan dikarakterisasi dari sumber alam (Delia, 2004). Karotenoid tersebut adalah pewarna alami yang larut dalam lemak, metabolit sekunder dari jenis terpenoid berupa suatu poliisoprenoid panjang (terdinframerahi atas 40 atom karbon/tetraterpen) yang me-ngandung ikatan rangkap dan tersusun dari rantai poliisoprena simetris terhadap pusat ikatan. Kedua molekulnya mengandung cincin sikloheksena yang tersubstitusi. Karotenoid juga merupakan sumber vitamin A yang dibutuhkan tubuh manusia untuk penglihatan, pertumbuhan dan perkembangan embrionik (Apel dan Bock, 2009). Kekurangan vitamin A dapat menyebabkan gangguan penglihatan dan kematian bayi. Defisiensi vitamin A diterapi dengan pemberian suplemen vitamin A atau dengan mengonsumsi buah atau sayur yang kaya akan kandungan karotenoid. Karotenoid dalam makanan umumnya adalah tetraterpenoid C40 terbentuk dari delapan unit isopren C5 bergabung kepala dengan ekor, kecuali di pusat di mana hubungan ekor-ke-ekor membalik urutan, menghasilkan molekul simetris (Basu dkk., 2001).

Senyawa-senyawa ini berasal dari phytoene, yang disintesis oleh reduktif dimerisasi geranylgeranyl pyrophosphate (GGPP), setelah langkah dehidrogenasinya, siklisasi, hidroksilasi, oksidasi dan epoksidasi (Tee dan Siong, 1991). Karotenoid secara struktural dibagi menjadi dua kelas utama. Pertama, karoten (misalnya, karoten, $\beta$-karoten, lycopene), yang secara eksklusif adalah hidrokarbon (tanpa molekul oksigen) (Aizawa dan Inakuma, 2007), dan kedua, xanthofil (misalnya, lutein, zeaxanthin, fucoxanthin dan astaxanthin) (Noviendri dkk., 2011), yang teroksigenasi mengandung hidroksil, metoksi, karboksil, keto, atau kelompok epoksi (Apel, 2009).

Penyerapan karotenoid lebih baik pada sayuran dan buah berwarna kuning atau oranye. Beta karoten dapat larut dalam lemak, tidak larut dalam ainframerah, mudah rusak karena teroksidasi pada suhu tinggi. Salah satu buah yang memiliki sumber karotenoid yaitu labu (Cucurbita moschata Duch ex Poiret). Buah labu kuning berbentuk bulat pipih, lonjong, atau panjang. Ukuran pertumbuhannya cepat sekali, mencapai 350 gram per hari. Labu kuning mengandung karotenoid (betakaroten), Vitamin A dan C, mineral, lemak serta karbohidrat (Fedha, 2008). Aktivitas terapeutik beta karoten, antara lain dapat meningkatkan sistem imunitas serta mencegah penyakit jantung dan kanker. Cucurbita moschata dikatakan sebagai rajanya beta karoten bukan karena bentuknya yang besar, tetapi sebab kandungan karotennya sangat tinggi, seperti lutein, zeaxanthin, dan karoten, yang memberi warna kuning pada labu kuning yang membantu melindungi tubuh dengan menetralkan radikal bebas (Durante dkk., 2014).

Isolasi senyawa beta karoten dari Cucurbita moschata dapat diawali dengan proses ekstraksi. Pemilihan metode ekstraksi menjadi sangat penting karena hasil ekstraksi dapat menentukan keberhasilan metode tersebut. Ekstraksi konvensional memakan waktu lebih lama dan melibatkan proses termal yang dapat merusak karotenoid. Oleh karena itu, dilakukan modifikasi ekstraksi konvensional dalam mengekstraksi senyawa beta karoten dari Cucurbita moschata (Carvalho, 2012 ). Tujuan penelitian ini adalah mengisolasi beta karoten dalam Cucurbita moschata dan dilakukan pemeriksaan purifikasi isolat menggunakan spektrofotometer UV-DAD dan spektrofotometri inframerah.

\section{METODE PENELITIAN}

Alat dan bahan

Alat yang digunakan pada penelitian antara lain Timbangan analitik (Ohaus), pisau, blender, timbangan (Krischef), gelas ukur $100 \mathrm{~mL}$ (Schott-Duran), corong $100 \mathrm{~mm}$ (Herma), erlenmeyer $250 \mathrm{~mL}$ (Iwaki), labu alas bulat, rotary evaporator (IKA type RV10 basic P diagonal), pipet ukur 5 
$\mathrm{mL}$ (Schott), pipet ukur $10 \mathrm{~mL}$ (Schott), chamber, bejana maserasi, plat KLT 250mm (Merck TLC), membran filter $0.2 \mathrm{~mm}$ (Sartorius CA), spuit injeksi $5 \mathrm{~mL}$ (Terumo), botol vial, alumunium foil, kolom kromatografi (Iwaki), statif dan clemp, cawan porselein $250 \mathrm{~mL}$, waterbath, spatula, lampu UV 254 dan 366nm, spektrofometer (UV-Vis LabTech), spektrofotometri inframerah (FT/INFRAMERAH- 6800typeA). Untuk bahan kimia, yang digunakan labu kuning sebanyak $1.364 \mathrm{~kg}$, aseton, petroleum eter, alkohol, n-heksana. Pelarut yang digunakan merupakan pelarut teknis.

\section{Prosedur kerja}

Preparasi sampel. Sampel diperoleh dari salah satu pusat swalayan di kota Malang, Jawa Timur seberat 1,364 kg. Sampel dibersihkan kulit dan dibuang bijinya. Sampel dipotong dan dihaluskan menggunakan blender.

Ekstraksi. Sampel yang sudah diblender ditimbang seberat 500 gram menggunakan timbangan KrisChef. Sampel dimasukkan dalam bejana maserasi. Disiapkan pelarut yang digunakan yakni aseton dan petroleum eter dengan perbandingan pelarut 1:1 sebanyak $1000 \mathrm{~mL}$. Perbandingan antara maserat dengan pelarut yaitu 1:2. Dituang pelarut dalam bejana yang sudah berisi maserat. Sesekali dilakukan pengadukan. Kemudian bejana disimpan di tempat yang terhindar dari cahaya selama \pm 24 jam. Selanjutnya dilakukan proses remaserasi sebanyak 2 kali. Filtrat hasil maserasi dipisahkan dan kemudian dievaporasi dengan rotary evaporator dengan kecepatan $80 \mathrm{rpm}$ dan suhu 50oC. Filtrat yang terpisah dari pelarut dimasukkan ke dalam cawan porselein dan diuapkan di atas waterbath pada suhu $50^{\circ} \mathrm{C}$. Ekstrak kental yang diperoleh kemudian ditimbang dan dihitung rendemennya.

Kromatografi Lapis Tipis dilakukan untuk mengetahui ada atau tidaknya senyawa beta karoten di dalam ekstrak, dilakukan pengujian kromatografi lapis tipis. Proses pemeriksaan senyawa beta karoten dilakukan dengan eluen n-heksan: aseton: etanol dengan perbandingan 1:1:2. Scan Spectrum dengan Spektrofotometer UV-Vis, dengan preparasi melarutkan ekstrak sebanyak 1 $\mathrm{ml}$ campuran pelarut petroleum eter : aseton (1:9). Metode ini dilakukan untuk mengetahui ada atau tidaknya senyawa beta karoten di dalam ekstrak Dilakukan pemeriksaan scan spectrum menggunakan instrumen spektrofotometer UV-Vis dengan rentang $350-550 \mathrm{~nm}$.

Fraksinasi dengan Kromatografi Kolom. Ekstrak sebanyak 1 gram ditimbang dan dilarutkan menggunakan etanol $8 \mathrm{~mL}$. Ditimbang silika gel254 sebanyak 5 gram. Silika dilarutkan dengan eluen yaitu aseton $10 \%$ dan petroleum eter $90 \%$. Suspensi silika dituang ke dalam kolom kromatografi yang sudah dibersihkan sebelumnya. Pelarut dibiarkan tersisa. Ekstrak dimasukkan dan dielusi menggunakan eluen. Fraksi yang diperoleh dihitung volumenya. Fraksi yang diperoleh dielusi dengan petroleum eter dan dilakukan pemeriksaan senyawa dengan kromatografi lapis tipis dengan eluen n- heksan:aseton: etanol dengan perbandingan 1:1:2.

KLT Preparatif dilakukan dengan melarutkan sejumlah ekstrak dalam etanol kemudian ditotolkan pada plat silika yang dipreparasi sebelumnya. Plat KLT Preparatif dibuat dengan menimbang 30 gram silika GF60 (Merck) dan dilarutkan dengan akuades. Plat dibuat dan dikeringkan dengan oven dengan suhu $115^{\circ} \mathrm{C}$ selama \pm 2 jam. Plat yang sudah ditotolkan dengan larutan ekstrak kemudian dielusi dengan eluen etanol: aseton: n-hexane dengan rasio (2:1:1). Plat yang selesai dielusi kemudian dikeringkan dan dilihat di bawah lampu UV 254 dan $266 \mathrm{~nm}$. Pemisahan yang terjadi ditandai dan dikerok menggunakan spatula. Serbuk isolat yang diperoleh dikumpulkan dan dibilas menggunakan kloroform : metanol perbandingan 1:1. Serbuk dibilas hingga tidak berwarna. Filtrat yang diperoleh dikeringkan pada suhu ruang.

Pemeriksaan kemurnian senyawa dengan spektrofotometri inframerah dan UV-DAD. Isolat yang diperoleh dikumpulkan. Isolat dihaluskan terlebih dahulu menggunakan mortinframerah dan stamper sebelum dilakukan uji menggunakan spektrofotometer inframerah FT/INFRAMERAH6800typeA pada bilangan gelombang $4000-400 \mathrm{~cm}-1$. Pengujian menggunakan UV-DAD dilakukan dengan memasukkan serbuk isolat dan ditutup rapat pada wadah sampel. Sebelum dilakukan analisis sampel, digunakan blanko plat $\mathrm{KBr}$. 


\section{HASIL DAN PEMBAHASAN}

\section{Kromatografi Lapis Tipis}

Identifikasi komposisi pigmen menggunakan KLT (Kromatografi Lapis Tipis) dengan plat silika gel sebagai fase diam/normal dan fase geraknya adalah $n$ heksan : aseton : etanol (1:1:2). Proses kerja kromatografi lapis tipis ini adalah, silika dapat membentuk ikatan hidrogen pada permukaanya, karena pada permukaan silika terdapat gugus hidroksil dan gugus silanol. Silika bersifat sangat polar. Jika fase gerak yang digunakan bersifat non-polar, maka senyawa yang bersifat polar akan semakin lama bertahan pada fase diam, sedangkan senyawa yang bersifat nonpolar akan cepat terelusi (prinsip like dissolve like).

Hasil kromatografi lapis tipis menggunakan cairan pengelusi ini terdampak noda sinar UV254nm ekstrak labu menampakkan 2 spot berwarna kuning pucat. Pada penampak noda sinar UV $366 \mathrm{~nm}$ spot terlihat namun hanya bercak kedua yang lebih terlihat jelas. Gambar pada UV 254 dapat dilihat seperti pada Gambar 1.

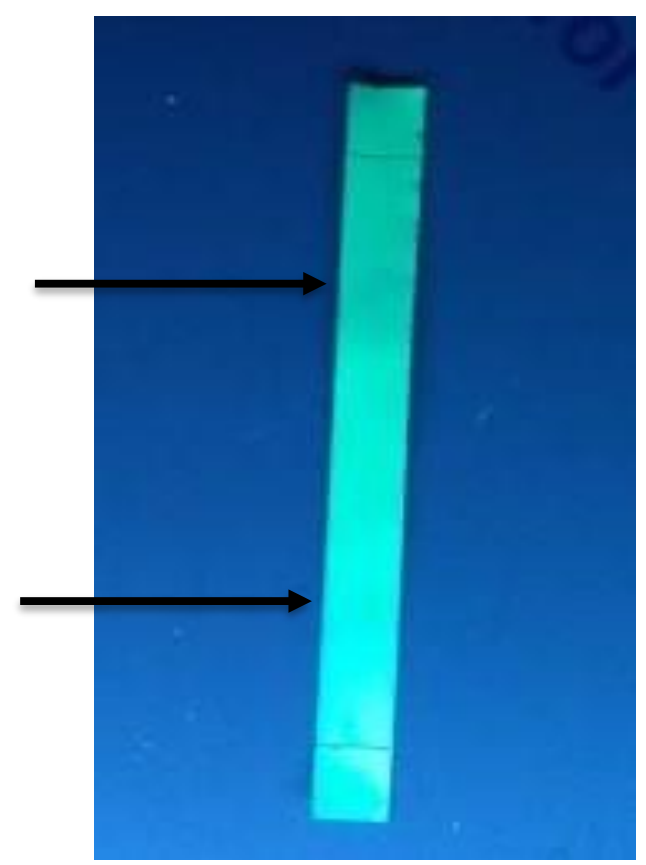

\section{Gambar 1. Hasil Pemisahan Ekstrak Labu Kuning dengan metode KLT pada UV 254}

Untuk dapat mengidentifikasi senyawa target yang dimiliki dalam sampel dianalisis menggunakan faktor reterdasi atau retardation factor (Rf). Untuk menghitung nilai $\mathrm{Rf}$ pada hasil KLT diperoleh dari perbandingan jarak yang ditempuh oleh pigmen dengan jarak yang ditempuh oleh pelarut. Hasil peneitian ini menunjukkan kisaran nilai Rf yang berbeda-beda, hasil penelitian ini menunjukkan kisaran Rf karotenoid berada pada bercak bagian atas dan Rf santofil berada pada bercak yang bagian bawah atau mendekati titik awal. Menandakan sampel labu kuning ini mengandung beta karoten.

\section{Spektrofotometri (UV-Vis LabTech)}

Ekstrak labu kuning digunakan untuk mengidentifikasi $\beta$ - karoten Dilakukan dengan melarutkan ekstrak sebanyak $1 \mathrm{ml}$ campuran pelarut petroleum eter:aseton (1:9) agar mengetahui absorbansi pada panajng gelombang tertentu yang menunjukkan adanya beta karoten. Berdasarkan hasil scan spectrum 300-600 nm pada spektrofotmetri (UV-Vis LabTech) pada panajng gelombang $441 \mathrm{~nm}$ dengan absorbansi 0,37775 menunjukkan adanya beta karoten. Hasil ini mendekati dengan referensi panjang gelombang $\beta$-karoten maksimal antara 425, 450, $478 \mathrm{~nm}$. Serapan-serapan ini muncul karena adanya transisi antara $\pi$ dan $\pi^{*}$ dan yang menunjukkan adanya ikatan rangkap terkonjugasi pada senyawa beta karoten. 


\section{Kromatografi Kolom}

Setiap fraksi-fraksi yang didapatkan dari metode fraksinasi kromatografi kolom, dilanjutkan dengan proses elusi pada plat KLT. Setelah diamati, didapatkan adanya kesamaan titik bercak pada fraksi ke 5, 6, 7, dan 8. Sehingga keempat fraksi ini digabungkan menjadi menjadi satu, kemudian kembali elusi namun menggunakan KLT preparatif, karena kemungkinan keempat fraksi gabungan tersebut dicurigai merupakan beta karoten.

\section{KLT Preparatif}

Hasil fraksinasi kromatografi kolom pada metode sebelumnya terrnyata tidak menunjukkan adanya bercak karena fraksi yang digunakan terlalu sedikit. Sehingga dilakukan kembali proses KLT preparatif isolat secara langsung dari ekstrak labu kuning yang dilarutkan dengan pelarut petroleum eter agar mendapatkan isolat yang lebih banyak dan tidak mengganggu hasil akhir inframerahnya. Isolat KLT preparatif ini dilakukan untuk melakukan pengujian \% T pada analisis Spektroskopi Inframerah.

\section{Spektroskopi Inframerah}

Analisis spektroskopi inframerah terhadap isolat (Gambar 2) memperkuat hipotesis dari hasil analisis spektroskopi UV bahwa isolat merupakan golongan senyawa karotenoid, dengan spektra bilangan gelombang $3310 \mathrm{~cm}-1$ menunjukkan ikatan O-H, pada serapan bilangan gelombang 2923 cm-1 menunjukan vibrasi ulur $\mathrm{C}-\mathrm{H}$ alifatik yaitu ikatan $\mathrm{C}-\mathrm{H}$ dari $\mathrm{CH}_{3}$, pada serapan bilangan gelombang 1621,84 cm-1 menunjukkan ikatan rangkap $\mathrm{C}=\mathrm{C}$, yang diperkuat oleh serapan $\mathrm{C}-\mathrm{H}$ dari ikatan rangkap terkonjugasi pada bilangan gelombang pada serapan bilangan gelombang 781,993 cm-1 dan 453,19 cm-1.

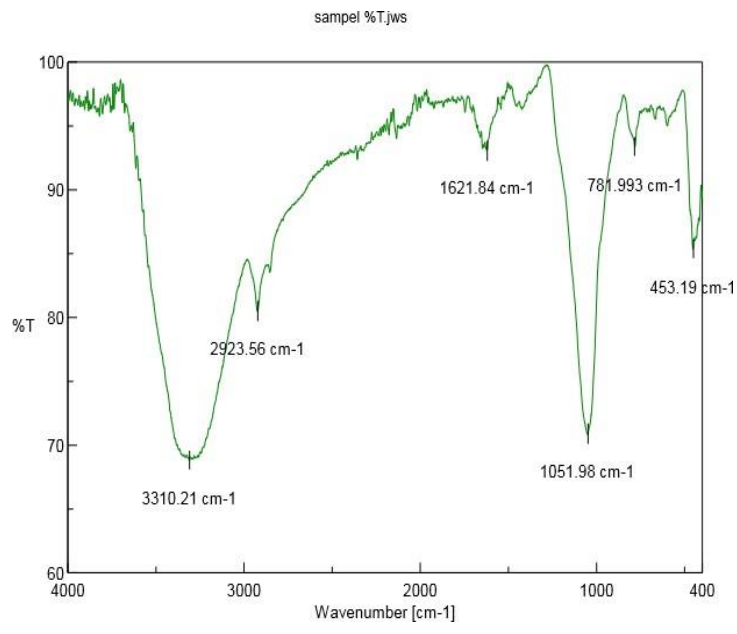

Gambar 2. Data Spektroskopi Inframerah

Untuk dapat mengetahui senyawa apa yang disolasi dalam penelitian ini, harus didukung dengan menggunakan instrumen dan metode lainnya, kalau hanya berdasarkan panjang gelombang pada spektrofotometri inframerah, tidak dapat mendukung sepenuhnya. Namun, berdasarkan hasil pmebacaan panjang gelombang inframerah, didukung kuat oleh keluarnya ikatan $\mathrm{O}-\mathrm{H}$ pada 3310 cm-1 untuk golongan xanthin, maka dapat dikatakan hasil penelitian ini adalah zeaxanthin dengan rumus molekul $\mathrm{C}_{4} \mathrm{OH}_{56} \mathrm{O}_{2}$. Lepasnya molekul $-\mathrm{OH}$ dalam struktur zeaxanthin sangat mungkin terjadi, karena senyawa karotenoid sangat rentan mengalami degradasi oleh cahaya selama proses analisis.

\section{KESIMPULAN}

Isolasi pigmen beta karoten dari ekstrak labu kuning (Cucurbita moschata Duch ex Poiret) diperoleh isolat berdasarkan hasil pengujian menggunakan KLT,spektrofotometri UV-Vis, KLT preparatif, DR-UV, dan spektroskopi inframerah, maka kemungkinan didapatkan komponen utama karotenoid dengan struktur yang hampir merah menyerupai senyawa zeaxanthin dengan rumus molekul $\mathrm{C}_{4} \mathrm{OH}_{56} \mathrm{O}_{2}$. 


\section{DAFTAR PUSTAKA}

Aizawa K, Inakuma T. Quantitation of Carotenoids in CommonlyConsumed Vegetables in Japan. Food Sci. Technol. Res., 2007, 13(3):247-252.

Apel W, Bock R. Enhancement of Carotenoid Biosynthesis in Transplastomic Tomatoes by Induced Lycopene-to-Provitamin A Conversion1[OA]. Plant Physiol., 2009. 151: 59-66.

Basu HN, Vecchio AJD, Flider F, Orthoefer FT. Nutritional andPotential Disease Prevention Properties of Carotenoids. J.A.O.C.S.,2001. 78(7): 665-675.

Delia B.HarvestPlus Handbook for Carotenoid Analysis. HarvestPlus, 2004.

Carvalho LMJ, Gomes PB, Godoy RL de O, Pacheco S, do Monte PHF, de Carvalho JLV, et al. Total carotenoid content, $\alpha$-carotene and $\beta$-carotene, of landrace pumpkins (Cucurbita moschata Duch): A preliminary study. Food Res Int [Internet]. 2012;47(2):337-40. Available from: http://dx.doi.org/10.1016/j.foodres.2011.07.040

Durante M, Lenucci MS, Mita G. Supercritical carbon dioxide extraction of carotenoids from pumpkin (Cucurbita spp.): A review. Int J Mol Sci. 2014;15(4):6725-40.

Fedha, M. Physicochemical Characterization and Food Application Potential of Pumpkin (Cucurbita Sp.) Fruit and Seed Kernel Flours. Food Science and Postharvest Technology in the Jomo Kenyatta University of Agriculture and Technology. 2008.

Tee, SiongE. Carotenoid composition and content of malaysian vegetables and fruits by the aoac and hplc methods. Food Chemistry. 1991; 41:309-339. 